\title{
An Analysis on Finding the Influencing Factors that Affecting Part Time Students to Complete Degree in Prescribed Time using Data Mining Techniques
}

\author{
B. Rama \\ M.Phil. (CS) Scholar \\ Department of CSA \\ SCSVMV University, Enathur, Kanchipuram
}

\author{
S. Prakasam, $\mathrm{PhD}$ \\ HOD \& Associate Professor \\ Department of CSA \\ SCSVMV University, Enathur, Kanchipuram
}

\begin{abstract}
Education is common for all. Education molds the mind of the people. The advantage of part time education is the people can work as well as they continue their studies. After marriage women have less chance to continue her education in regular basis. In such case part time education is useful for them. For men according to their family situation they can't study in regular basis. In part time education they can work and earn money and they can study. The main objective of this work is to find the factors that affecting part time student's degree completion in prescribed time. The purpose of this work is to investigate the obstacles that stand in the way of increasing part time degree completion. The Questionnaire was designed to analyze the influencing factors. Family related reasons, Student related reason and Employment related reasons from these situations data are collected. The WEKA software tool is used for implementation since it is widely used for research purpose in data mining.
\end{abstract}

\section{Keywords}

WEKA,Data mining

\section{INTRODUCTION}

Education is most important for all. Education plays an important role in everyone life. For living a luxurious or better life we should be educated. Education plays a vital role in every ones success and personal growth. All of us must aim to ensure that each citizen of our nation is educated and independent. Part time degree is most suitable for one who is working as a full time employee and also continuing his/her studies. There is some problem may occur in part time degree completion in prescribed time. A survey has been conducted during March - May 2015 with part time students of 275.The author collected data from the students who are struggling and not able to complete the degree in prescribed time. The Questionnaire was distributed to the students' face to face contact in and around Kanchipuram. The WEKA software tool is used for implementation since it is widely used for research purpose in data mining. In this dissertation author used ranking algorithm. This analysis shows to identify the major affecting factors are: Difficult to focus in studies, To take care of kids, Project difficult, Lack of self- motivation, Professional responsibility.

\section{LITERATURE REVIEW}

\section{- Part Time Students in Higher Education}

Part Time Students refers to as non-traditional students who pursues higher education typically after reaching physical maturity and possessing responsibilities related to family and employment.

\begin{abstract}
- Part Time Students Population:
Part time students have a long history in higher education. The earliest universities include Takshasila and Nalanda in Asia and the medieval universities in Europe were created and organized for part time students. The Trends Report (2007) reported from 1976-1992 part time enrollment grew by $65 \%$ (percent) or 125,000 to a peak of 316,000 in 1992. Green and Powell (2005) highlight four factors underlying lengthy completion times. The factors are Individual, Structural, Academic and Environmental.
\end{abstract}

\section{- Employment Factors:}

Employment factor is one of the most important factor, that differentiate part time students from full time students. Working experience of part time learners are viewed as continually enriching and contributing their learning process.

\begin{abstract}
- Risk Factors for Delaying Graduation:
Part time degree delays when students are enter into a career, being contributing to the economy and making salary said Ben Kohl president of the Kansas Association of Student Financial Aid Administrators. Students get trouble when they go down the road toward a major and have to switch because it change their minds said Ed Venit a senior director with the education advisory board. Kohl recommends having a strong idea of major before begin college student should have a fairly firm idea of the field of study. A recent case study on Students Dropout Risk Assessment by sweta rai et.al on predicting undergraduate courses of computer science Student's instant dropout or after the first semester using educational data mining. For this purpose the preliminary data of 220 students were collected randomly to find out dropout rates and reasons. The main reason recorded for students dropout are 1) Personal factor is homesickness 2)Educational factor is learning problems and 3)Institutional factor such as campus environment and many rules in hostel life. The information generated will be very useful for best planning and implementation of educational program and infrastructure and to increase the enrollment rate of students in ICT courses at this university.
\end{abstract}

\section{METHODOLOGY}

In this work data mining technique based on analysis finding factor that delay to complete the part time degree using chisquared attribute evaluator and ranker search method in ranking algorithm. The data analysis helps us to provide a better understanding of large set of data. 


\subsection{Questionnaire Design}

The researcher was very careful to develop a questions clearly. So that respondent have no doubt to answer the question. Researcher use five point scale for each questions. "strongly agree", "agree", "neutral", "disagree", "strongly disagree" where the middle option is "neither agree nor disagree" or "undecided" is available and thus minimized central tendency basis.

\subsection{Tools}

WEKA (Waikato Environment for Knowledge Analysis) is a popular software written in java developed at the university of Waikato. WEKA contains collection of visualization tools and algorithms for data analysis. WEKA supports several standard data mining tasks more specifically data preprocessing, classification, clustering, association, attribute selection and visualization. WEKA consist of Explorer, Knowledge flow, Experimenter and Simple command line interface. WEKA's main user interface is Explorer.

SPSS is most widely used statistical software. The graphical user interface has two views which can be toggled by clicking on the tab in the bottom of the left in SPSS window. The data view shows the spread sheet view of the cases(rows) and variable view shows variables(columns). The data cells only contain numbers or text. The variable view displays the metadata dictionary each row represents a variable and shows variable name, variable label, value label, measurement type and variety of other characteristics. SPSS 16.0 version is used in this research.

\section{ANALYSIS}

\subsection{Experiments using WEKA for Ranking Algorithm}

Data consists of list of items with some partial order. This order is induced by giving a numerical or ordinal score or binary judgement. The ranking algorithm is used to find the influencing factor of the large set of data.

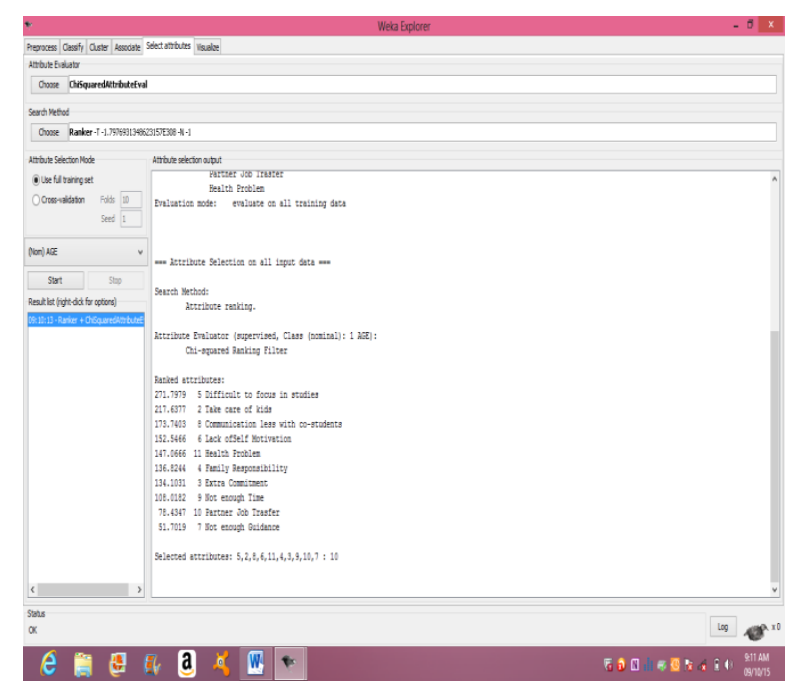

Fig 1.1 Screen shot for select attribute in ranking family Related Reason

In this attribute evaluator method chosen is chi-squared attribute evaluator and search method chosen is Ranker. Attribute selection mode is use full training set. Here output percentage of the given is clearly see the much influencing factors are Difficult to focus in studies 271.7979, Take care of kids 217.6377, Communication less with co-students
173.7403 and Lack of self-motivation 152.5466. These are the highly influencing Family based factors which affects the part time degree completion in prescribed time. Applied ChiSquared Ranking algorithm on the data based on age.

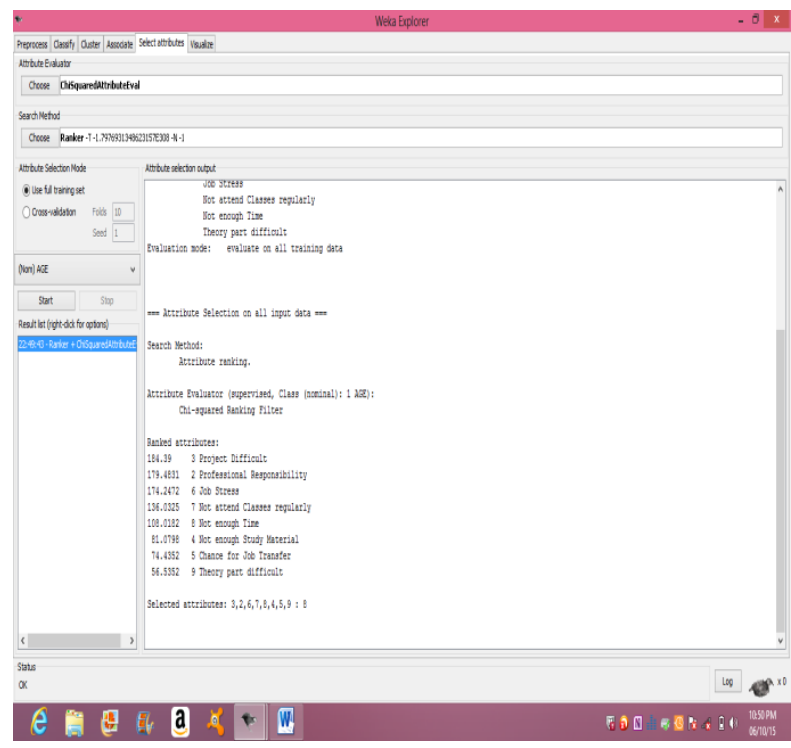

Figure 1.2 Screen shot for select attribute in ranking Employment Related Reason

In this attribute evaluator method chosen is chi-squared attribute evaluator and search method chosen is Ranker. Attribute selection mode is use full training set. Here output percentage of the given is clearly see the much influencing factors are Project Difficult 184.39, Professional Responsibility 179.4831, Job Stress 174.2472 and Not attend classes regularly 136.0325 . These are the highly influencing employment based reasons which affects the part time degree completion in prescribed time.

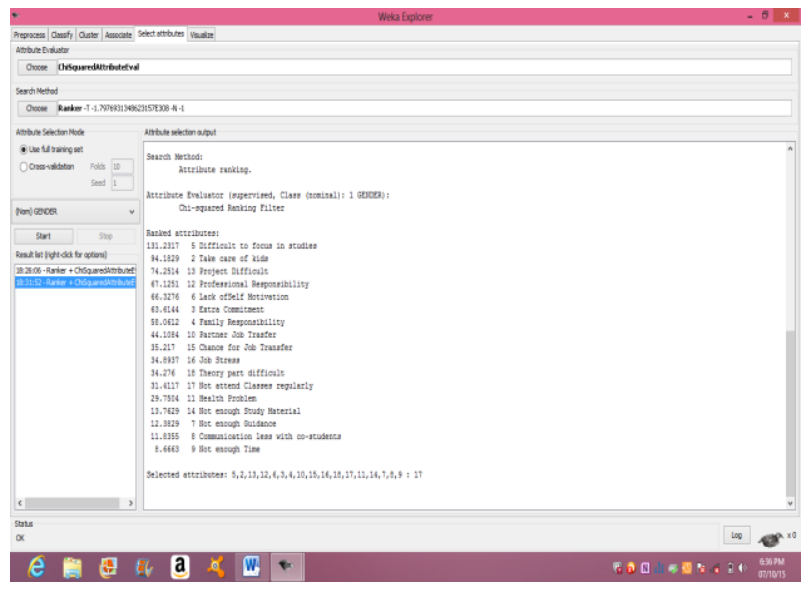

Figure 1.3 Screen shot for ranking based on gender

In this attribute evaluator method chosen is chi-squared attribute evaluator and search method chosen is Ranker. Attribute selection mode is use full training set. Here output percentage of the given is clearly see the much influencing factors are Difficult to focus in studies 131.2317, Take care of kids 94.1829, Project Difficult 74.2514, Professional Responsibility 67.1251. Researcher ranked these attributes based on gender. 


\subsection{Frequency Table}

The frequency table helps to understand the respondents based on gender and age

Table 1.1 No of respondents based on gender

\begin{tabular}{|l|c|c|}
\hline Gender & No. of. respondents & Percentage \\
\hline Male & 133 & 48.36 \\
Female & 142 & 51.64 \\
Total & 275 & 100.00 \\
\hline
\end{tabular}

Table 1.2 No of respondents based on age

\begin{tabular}{|l|c|c|}
\hline Age & No. of. respondents & Percentage \\
\hline $21-24$ & 90 & 32.73 \\
$25-28$ & 125 & 45.45 \\
$29-32$ & 43 & 2.54 \\
$33-35$ & 7 & 3.64 \\
$36-40$ & 10 & 15.64 \\
Total & 275 & 100.00 \\
\hline
\end{tabular}

\subsection{Cross Tabulation}

Table 1.3 Age Vs difficult to focus in studies

\begin{tabular}{|c|c|c|c|c|c|c|}
\hline \multirow[b]{2}{*}{$\begin{array}{l}\text { age vs difficult to } \\
\text { focus in studies }\end{array}$} & \multicolumn{5}{|c|}{ Difficult to focus in studies } & \multirow[b]{2}{*}{ Total } \\
\hline & AGREE & DISAGREE & NEUTRAL & $\begin{array}{l}\text { STRONGLY } \\
\text { AGREE }\end{array}$ & $\begin{array}{l}\text { STRONGLY } \\
\text { DISAGREE }\end{array}$ & \\
\hline \multicolumn{7}{|l|}{ Age } \\
\hline $21-24$ & 28 & 10 & 19 & 7 & 26 & 90 \\
\hline $25-28$ & 73 & 4 & 9 & 21 & 18 & 125 \\
\hline $29-32$ & 26 & 1 & 2 & 13 & 1 & 43 \\
\hline $33-35$ & 3 & 1 & 1 & 1 & 1 & 7 \\
\hline $36-40$ & 6 & 1 & 1 & 1 & 1 & 10 \\
\hline Total & 136 & 17 & 32 & 43 & 47 & 275 \\
\hline
\end{tabular}

From the above cross tabulation student's one of the reason for delaying part time degree completion is difficult to focus in studies. Among 90 members of age from 21-24 have high influencing percent is 28 of them are agree. Among 125 members of age from 25-28 have high influencing percent is 73 of them are agree. Among 43 members of age from 29-32 have high influencing percent is 26 of them are agree. Among 7 members of age from 33-35 have high influencing percent is 3 of them are agree. Among 10 members of age from 36-40 have high influencing percent is 6 of them are agree. From the above tabulation the one of the most influencing factor for delaying degree completion is difficult to focus in studies.

Table 1.4 Age Vs take care of kids

\begin{tabular}{|c|c|c|c|c|c|c|}
\hline \multirow{2}{*}{$\begin{array}{l}\text { Age vs take care } \\
\text { of kids }\end{array}$} & \multicolumn{5}{|c|}{ Take care of kids } & \multirow[b]{2}{*}{ Total } \\
\hline & AGREE & DISAGREE & NEUTRAL & $\begin{array}{l}\text { STRONGLY } \\
\text { AGREE }\end{array}$ & $\begin{array}{l}\text { STRONGLY } \\
\text { DISAGREE }\end{array}$ & \\
\hline \multicolumn{7}{|l|}{ age } \\
\hline $21-24$ & 20 & 29 & 21 & 6 & 14 & 90 \\
\hline $25-28$ & 42 & 12 & 28 & 12 & 31 & 125 \\
\hline $29-32$ & 28 & 0 & 12 & 2 & 1 & 43 \\
\hline $33-35$ & 5 & 0 & 2 & 0 & 0 & 7 \\
\hline $36-40$ & 5 & 0 & 2 & 0 & 3 & 10 \\
\hline Total & 100 & 41 & 65 & 20 & 49 & 275 \\
\hline
\end{tabular}

From the above cross tabulation student's one of the reason for delaying part time degree completion is to take care of kids. Among 90 members of age from 21-24 have high influencing percent is 29 of them are disagree. Among 125

members of age from 25-28 have high influencing percent is 42 of them are agree. Among 43 members of age from 29-32 have high influencing percent is 28 of them are agree. Among 7 members of age from 33-35 have high influencing percent is
5 of them are agree. Among 10 members of age from 36-40 have high influencing percent is 5 of them are agree.

From the above tabulation the one of the most influencing factor for delaying degree completion is to take care of kids.

\section{CONCLUSION}

Part time student is entirely different from full time students. Full time students have more time to concentrate in studies. In part time degree the students want to manage both carrier and education. Because of their profession and family related 
reason they choose part time degree. But the same reason affects the students to complete the degree in prescribed time. The result achieved by applying data mining algorithm. The researcher use ranking algorithm based on their family and employment related reason. Result of ranking algorithm is Difficult to focus in studies 131.2317, Take care of kids 94.1829, Project Difficult 74.2514, Professional Responsibility 67.1251.These are the influencing factors among part time students degree completion in prescribed time. So the students want to give equal importance to their responsibilities and their studies. They want to achieve success in their life. The conclusion made from the conducted research will be used for increasing part time student academic success.

\section{REFERENCES}

[1] Shale, D., \& Roche, J. (1998). Not all part-time students are the same. Presented to the Canadian Institutional Research and Planning Association Annual Conference, October 1998. Office of Institutional Analysis, University of Calgary.

[2] Ahern, K. \&Manathunga, C. (2004) Clutch-starting stalled research students.Innovative Higher Education, 28 (4), 237-254.

[3] Green, H. and Powell S. (2005) Doctoral Study in Contemporary Higher Education. Maidenhead: SHRE and Open University Press.

[4] Leonard, D., Metcalfe, J., Becker, R. and Evans, J. (2006) Review of literature on the impact of working context and support on the postgraduate research student learning experience. Higher Education Academy and UK GRAD Programme.

[5] Ibrahim, Norhayati, "Exploring factors affecting parttime students academic success in Malaysian polytechnic institutions" (2011).Graduate Thesesand Dissertations.Paper 10060.http://lib.dr.iastate.edu/etd/10060

[6] Bean, J. P., \&Metzner, B. S. (1985). A conceptual model of non-traditional undergraduate student attrition. Review of Educational Research, 55(4), 485-540.

[7] Berker, A. \& Horn, L. (2004). Work first, study second: adult undergraduate who combine employment and post secondary enrolment. Education Statistics Quarterly. 5(3), 122-134
[8] Bui, K. V. T. (2002).First-generation college students at a four-year university: Background characteristics, reasons for pursuing higher education, and first-year experiences. College Student Journal, 36(1), 3-11.

[9] Carney-Crompton, S., \& Tan, J. (2002). Support systems, psychological functioning, and academic performance of non-traditional female students. Adult Education Quarterly, 52(2), 140-154.

[10] S. Dhivya M.Phil(cs) Research Scholar SCSVMV University Enathur, Kanchipuram. S. Prakasam, Ph.D Assistant Professor Department of CSA, SCSVMV University Enathur, Kanchipuram.An Analysis on finding the influencing factor of preventing the employment among the educated women using data mining techniques. International Journal of Computer Applications (0975 - 8887) Volume 101- No. 7, September 2014

[11] Factors preventing young people from continuing in education

[12] J.F Superby and J.P. Vandamme N. Meskens Determination of factors influencing the achievement of the first-year university students using data mining methods Production and operations management Department, Catholic University of Mons, Chaussee de binch 151,7000 Mons, Belgium.

[13] M Prema and S Prakasam Effectiveness of Data Mining based E-learning system (DMBELS). International Journal of Computer Applications (0975-8887) Volume 66-No.19,March 2013.

[14] Students' Dropout Risk Assessment in Undergraduate Courses of ICT at Residential University - A Case Study.

[15] Importance of education article the Hindu

[16] https://en.wikipedia.org/wiki/Parttime_learner_in_higher_education

[17] Know Your Risk Factors for Delaying Graduation, Accumulating More Debt

[18] https://www.learning.ox.ac.uk

[19] https://en.wikipedia.org/wiki/weka_(machine_learning)

[20] https://en.wikipedia.org/wiki/spss. 